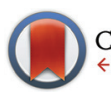

CrossMark

Cite this: Dalton Trans., 2016, 45 19322

Received 27th September 2016, Accepted 10th November 2016 DOI: $10.1039 / \mathrm{c} 6 \mathrm{dt} 03751 \mathrm{~h}$ www.rsc.org/dalton

\title{
Birnessite-type $\mathrm{MnO}_{2}$ nanosheet arrays with interwoven arrangements on vapor grown carbon fibers as hybrid nanocomposites for pseudocapacitors $\uparrow$
}

\author{
S. Chandra Sekhar, Goli Nagaraju, Sung Min Cha and Jae Su Yu*
}

\begin{abstract}
Manganese dioxide nanosheet arrays with interconnected arrangements are easily synthesized on vapor grown carbon fibers $\left(\mathrm{MnO}_{2} \mathrm{NSAs}\right.$ (aVCFs) by a simple wet-chemical method at low temperature. The conductive nature of the VCFs serves as a scaffold and easily reduces potassium permanganate species for the formation of hierarchical $\mathrm{MnO}_{2}$ NSAs aVCFs. When utilized as an electroactive material for pseudocapacitors, the sophisticated configuration of the nanocomposite provides an effective electrochemical activity and an electron pathway for higher electrochemical performance in $1 \mathrm{M} \mathrm{Na}_{2} \mathrm{SO}_{4}$ aqueous solution. The hierarchical $\mathrm{MnO}_{2}$ NSAs@VCFs exhibit a maximum specific capacitance of $115.3 \mathrm{~F} \mathrm{~g}^{-1}$ at a current density of $0.5 \mathrm{~A} \mathrm{~g}^{-1}$ with an excellent cycling stability of $85.6 \%$ after 2000 cycles at a current density of $5 \mathrm{~A} \mathrm{~g}^{-1}$. Such facile and cost-effective fabrication of a metal oxide nanocomposite with improved electrochemical performance allows it to be considered as a promising electroactive material for energy storage devices.
\end{abstract}

\section{Introduction}

Nowadays, facing the challenges regarding scientific and technological problems of increasing energy consumption is the most serious issue for humanity. Also, the diminishing supply of fossil fuels is problematic as more energy is needed for many urbanizing nations. ${ }^{1-3}$ These factors are greatly influencing the power infrastructure in producing the energy needed. ${ }^{4}$ So, it is essential to develop various energy storage devices to replace swiftly depleting fossil fuels without any hazards to the environment. ${ }^{5-7}$ Among the available energy storage devices, supercapacitors have attracted a great deal of attention and are used in many electronic devices because of their light weight, reliable operation, fast charging-discharging and long lifetime. ${ }^{8-10}$ Generally, the energy storage mechanism in supercapacitors is classified into two types, i.e., electric double layer capacitors (EDLCs) and pseudocapacitors. ${ }^{6}$ In EDLCs, energy storage takes place non-faradaically by accumulating electric charge at the interface between the electrolyte and electrode material. Reduced graphene oxide, activated carbon, etc. are

Department of Electronics and Radio Engineering, Institute for Wearable Convergence Electronics, Kyung Hee University, 1 Seocheon-dong, Giheung-gu, Yongin-si, Gyeonggi-do 446-701, Republic of Korea.E-mail: jsyu@khu.ac.kr; Fax: +82-31-206-2820; Tel: +82-31-201-3820

$\dagger$ Electronic supplementary information (ESI) available. See DOI: 10.1039/ c6dt03751h mostly used as active materials in EDLCs. ${ }^{11}$ Meanwhile, pseudocapacitors store electric charge at the electrode-electrolyte interface by continuous redox reactions within the active material. ${ }^{12}$ Transition metal oxides and conducting polymer based materials are generally used as an active material for pseudocapacitors. ${ }^{13,14}$ Because of the redox chemistry process, pseudocapacitive materials possess higher electrochemical performances compared to EDLC materials. ${ }^{15,16}$

So far, transition metal hydroxide/oxide based nanostructures, including $\mathrm{RuO}_{2}, \mathrm{Ni}(\mathrm{OH})_{2}, \mathrm{Co}_{3} \mathrm{O}_{4}$, Ni-Co hydroxide, $\mathrm{MnO}_{2}$, etc., have been utilized as active materials in pseudocapacitors. ${ }^{17-21}$ Each of these materials has their own unique advantages and disadvantages. Among these materials, $\mathrm{MnO}_{2}$ especially has been considered as a promising candidate for use in pseudocapacitors because of its high theoretical capacitance, low cost, environmentally-friendly feature and abundant availability in nature. Accordingly, $\mathrm{MnO}_{2}$ based nanostructures with various morphologies such as nanowires, nanosheets, and flower-like structures have been prepared under various growth methods for pseudocapacitors. ${ }^{22-25}$ The relatively low electrical conductivity of $\mathrm{MnO}_{2}$ leads to the use of a small amount of material during the electrochemical process, which results in a lower capacitance. However, there have been some obstacles in the fabrication of $\mathrm{MnO}_{2}$ based supercapacitors. ${ }^{26,27}$ To improve the capacitance performance, doping of $\mathrm{MnO}_{2}$ with different metals or incorporation of conductive additives such as carbon nanotubes, graphene 
oxide, conducting polymers, etc. is essential. ${ }^{28,29}$ Although $\mathrm{MnO}_{2}$ transition metal hybrid composites have high capacitance, they cause a loss of capacitance during the cycling process. ${ }^{30}$ Therefore, finding a novel and cost-effective conductive material to be incorporated into $\mathrm{MnO}_{2}$ is a promising approach to improve the electrochemical performance. ${ }^{31}$ of several conducting materials, vapor grown carbon fibers (VCFs) are considered as an effective candidate because of their abundance, low cost, good electrical conductivity, highly accessible surface and robust electrochemical resistibility against several electrolytes. ${ }^{32,33}$ Therefore, the incorporation of VCFs into $\mathrm{MnO}_{2}$ could be expected to offer a better capacitive performance.

In this work, we report a simple and cost-effective approach to synthesize a hybrid composite of $\mathrm{MnO}_{2}$ nanosheet arrays coated onto VCFs $\left(\mathrm{MnO}_{2}\right.$ NSAs@VCFs) by a wet-chemical method. The as-prepared composite provides unique properties including good electrical conductivity and open porous structure, which are favorable for the intercalation-deintercalation of electrolyte ions with the electrochemically active species. Thus, a higher electrochemical performance including excellent cycling stability is presented.

\section{Experimental section}

\subsection{Chemicals}

VCFs were purchased from Showa Denko K.K, Japan. Potassium permanganate $\left(\mathrm{KMnO}_{4}\right.$, ACS reagent, $\left.\geq 99.0 \%\right)$, sulfuric acid $\left(\mathrm{H}_{2} \mathrm{SO}_{4}\right)$ (99.999\% pure), nitric acid $\left(\mathrm{HNO}_{3}\right)$ and sodium sulfate $\left(\mathrm{Na}_{2} \mathrm{SO}_{4}\right)$ were purchased from Sigma Aldrich Corp., South Korea. Polyvinylidene fluoride (PVdF, $\left.-\left(\mathrm{C}_{2} \mathrm{H}_{2} \mathrm{~F}_{2}\right)_{n}{ }^{-}\right)$and $\mathrm{N}$-methyl-2-pyrrolidone (NMP, $\mathrm{C}_{5} \mathrm{H}_{9} \mathrm{NO}$ ) were obtained from Daejung Chemicals Ltd, South Korea.

\subsection{Synthesis of $\mathrm{MnO}_{2} \mathrm{NSAs@VCFs}$}

The hierarchical $\mathrm{MnO}_{2}$ NSAs@VCFs nanocomposite was synthesized via a simple and green wet-chemical method. At first, the VCFs were acid-treated with nitric acid under reflux condition for $6 \mathrm{~h}$ for functionalization. After that, the VCFs were cleaned with de-ionized (DI) water several times to remove the acidic species and dried at $60^{\circ} \mathrm{C}$ for $2 \mathrm{~h}$. Then, the acid-treated VCFs $(50 \mathrm{mg}$ ) were dispersed in a beaker containing $100 \mathrm{ml}$ of DI water and $25 \mathrm{mM}$ of $\mathrm{KMnO}_{4}$ was added to the above solution under magnetic stirring. After $10 \mathrm{~min}, 1 \mathrm{ml}$ of $\mathrm{H}_{2} \mathrm{SO}_{4}$ was added dropwise to the above mixture and heated at $80{ }^{\circ} \mathrm{C}$ for $6 \mathrm{~h}$ on a hotplate under vigorous stirring. Finally, the precipitate was collected by washing with water after it cooled down to room temperature (RT) and was dried at $60{ }^{\circ} \mathrm{C}$ overnight.

\subsection{Characterization}

The surface morphologies of the $\mathrm{MnO}_{2}$ NSAs@VCFs were characterized using a field-emission scanning electron microscope (FE-SEM, Carl Zeiss, LEO SUPRA 55) equipped with an energy-dispersive X-ray spectrometer (EDX). The crystallinity of a prepared sample was observed by using an X-ray diffractometer (XRD, M18XHF-SRA, Mac Science Ltd) with $\mathrm{Cu} \mathrm{K} \alpha$ radiation $(\lambda=0.15406)$. Raman spectra of the prepared samples were analyzed using a high-resolution Raman spectrometer (HR-Raman Spectrometer, inVia) employing an argon ion laser with an incident wavelength of $514 \mathrm{~nm}$.

\subsection{Electrochemical measurements}

The electrochemical properties of the $\mathrm{MnO}_{2}$ NSAs@VCFs were characterized by using an IVIUMSTAT electrochemical workstation (IVIUM Technologies) in a three electrode system at RT. Cyclic voltammetry (CV), galvanic charge-discharge (GCD) and electrochemical impedance spectroscopy (EIS) measurements were conducted using the synthesized $\mathrm{MnO}_{2}$ NSAs@VCFs composite coated carbon cloth as a working electrode, platinum wire as a counter electrode and $\mathrm{Ag} / \mathrm{Ag} \mathrm{Cl}$ as a reference electrode in $1 \mathrm{M} \mathrm{Na}_{2} \mathrm{SO}_{4}$ electrolyte solution. Here, the working electrode was prepared by mixing 80 wt $\%$ of $\mathrm{MnO}_{2}$ NSAs@VCFs, $10 \mathrm{wt} \%$ of super P carbon black and $10 \mathrm{wt} \%$ of $\mathrm{PVdF}$ as a binder. The mixture was well ground using an agate mortar and then NMP solvent was added dropwise to form a slurry. The obtained slurry was then coated uniformly on the piece of carbon cloth $\left(1 \times 1 \mathrm{~cm}^{2}\right)$ and dried at RT. After drying, the electrodes were placed on a hotplate at $120^{\circ} \mathrm{C}$ for $3 \mathrm{~h}$. The specific capacitance of the active material was calculated using the following formula: ${ }^{34,35}$

$$
C_{\mathrm{s}}=\frac{I \times \Delta t}{m \times \Delta V}
$$

where $C_{\mathrm{s}}$ is the specific capacitance $\left(\mathrm{F} \mathrm{g}^{-1}\right), I$ is the discharge current (A), $\Delta t$ is the discharge time (s), $m$ is the mass (g) of the active material and $\Delta V$ is the potential window $(\mathrm{V})$.

\section{Results and discussion}

Fig. 1 shows a schematic diagram of the fabrication procedure for $\mathrm{MnO}_{2}$ NSAs@VCFs. Here, cost-effective, anticorrosive and electrically conductive VCFs were chosen as a scaffold for the growth of $\mathrm{MnO}_{2}$ NSAs (Fig. 1(a)). Initially, the VCFs were

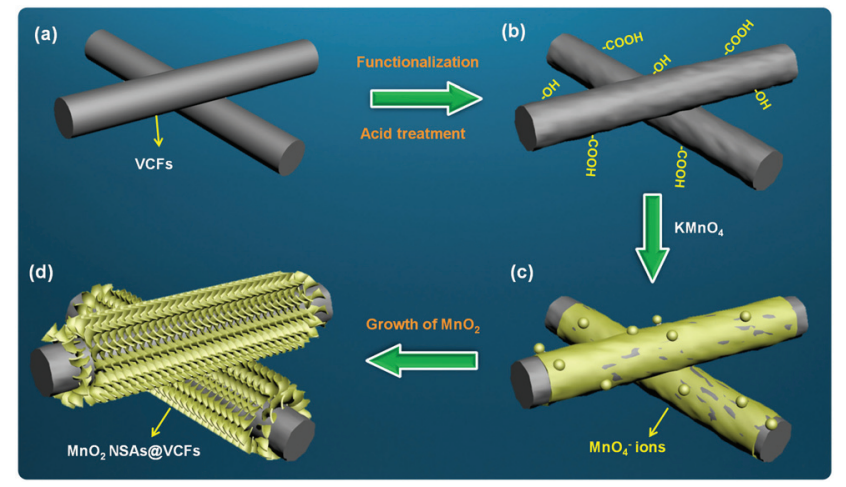

Fig. 1 Schematic illustration of the fabrication procedure for the $\mathrm{MnO}_{2}$ NSAs@VCFs. 
acid-treated to enhance the dispersion and to decrease the hydrophobic nature and van der Waals forces among them, as shown in Fig. 1(b). The as-functionalized VCFs were mixed with $\mathrm{KMnO}_{4}$ to prepare the $\mathrm{MnO}_{2}$ NSAs. The VCFs served as a sacrificial reductant and the $\mathrm{KMnO}_{4}$ acted as an oxidant, with the intention to convert the dissolved $\mathrm{Mn}^{7+}$ to $\mathrm{Mn}^{4+}$. As a result, the insoluble $\mathrm{MnO}_{2}$ NSAs were deposited on the surface of the VCFs. During the synthesis, a few drops of $\mathrm{H}_{2} \mathrm{SO}_{4}$ were added to the growth solution, which led to the uniform dissolution of VCFs in DI water and provided a higher degree of oxidation to the VCFs. Then, the permanganate $\left(\mathrm{MnO}_{4}{ }^{-}\right)$ions were gradually absorbed and precipitated on the surface of the oxidized VCFs via an interaction between the remaining $\mathrm{KMnO}_{4}$ and the hydroxyl groups of VCFs under the thermal conditions as shown in Fig. 1(c). The formation of $\mathrm{MnO}_{2}$ NSAs@VCFs during this synthesis process is demonstrated by the following equation: ${ }^{36,37}$

$4 \mathrm{KMnO}_{4}+3 \mathrm{C}+2 \mathrm{H}_{2} \mathrm{SO}_{4} \stackrel{\mathrm{H}_{2} \mathrm{O}}{\longrightarrow} 4 \mathrm{MnO}_{2}+3 \mathrm{CO}_{2}+2 \mathrm{~K}_{2} \mathrm{SO}_{4}+2 \mathrm{H}_{2} \mathrm{O}$.

The redox reaction between the $\mathrm{KMnO}_{4}$ and VCFs occurred slowly in the solution under stirring at RT. Upon heating at $80^{\circ} \mathrm{C}$, the growth rate increased rapidly, which resulted in the formation of $\mathrm{MnO}_{2}$ NSAs on the VCF surfaces as shown in Fig. 1(d). Meanwhile, under neutral growth conditions without the addition of $\mathrm{H}_{2} \mathrm{SO}_{4}$ to the growth solution, the $\mathrm{KMnO}_{4}$ acted as a 'weak oxidizing agent' due to the much lower posi- tive electrode potential than that found under acidic conditions. Such conditions are unfavorable for the reduction of $\mathrm{MnO}_{4}{ }^{-}$ions by water. ${ }^{36}$ In addition, in the absence of the VCFs in the growth solution, we did not observe any product after the completion of the growth process. This indicates that the VCFs not only play a crucial role in reducing the $\mathrm{KMnO}_{4}$ under acidic conditions, but are also helpful in the growth of the $\mathrm{MnO}_{2}$ NSAs on their surfaces.

The morphologies of the bare VCFs and the hierarchical $\mathrm{MnO}_{2}$ NSAs@VCFs composite are shown in Fig. 2. As shown in Fig. 2(a), the VCFs showed a regular fiber-like structure and their diameter was found to be $\sim 120 \mathrm{~nm}$. After completion of the growth process, as displayed in Fig. 2(b), the prepared sample was uniformly decorated on the surface of VCFs. As can be clearly seen in the increased magnification image (Fig. 2(c)), forest-like $\mathrm{MnO}_{2}$ NSAs were densely gathered on the VCFs, to give an increased diameter of $\sim 415 \mathrm{~nm}$ as compared to the bare VCFs. This indicates that a $\mathrm{MnO}_{2}$ NSA layer had a height of $295 \mathrm{~nm}$. Moreover, each NSA had a thickness of around 16-22 $\mathrm{nm}$ as shown in Fig. 2(d). From the EDX analysis of the $\mathrm{MnO}_{2}$ NSAs@VCFs composite (Fig. 2(e)), it can be observed that the presence of $\mathrm{Mn}, \mathrm{O}$ and $\mathrm{C}$ was quite evident without any impurities. Also, the elemental mapping images showed that $\mathrm{Mn}$ and $\mathrm{O}$ elements were uniformly distributed on the VCFs, which have a high $\mathrm{C}$ content as shown in Fig. 2(f).

The crystalline structure of the prepared material was characterized by XRD analysis. Fig. 3(a) shows the XRD patterns
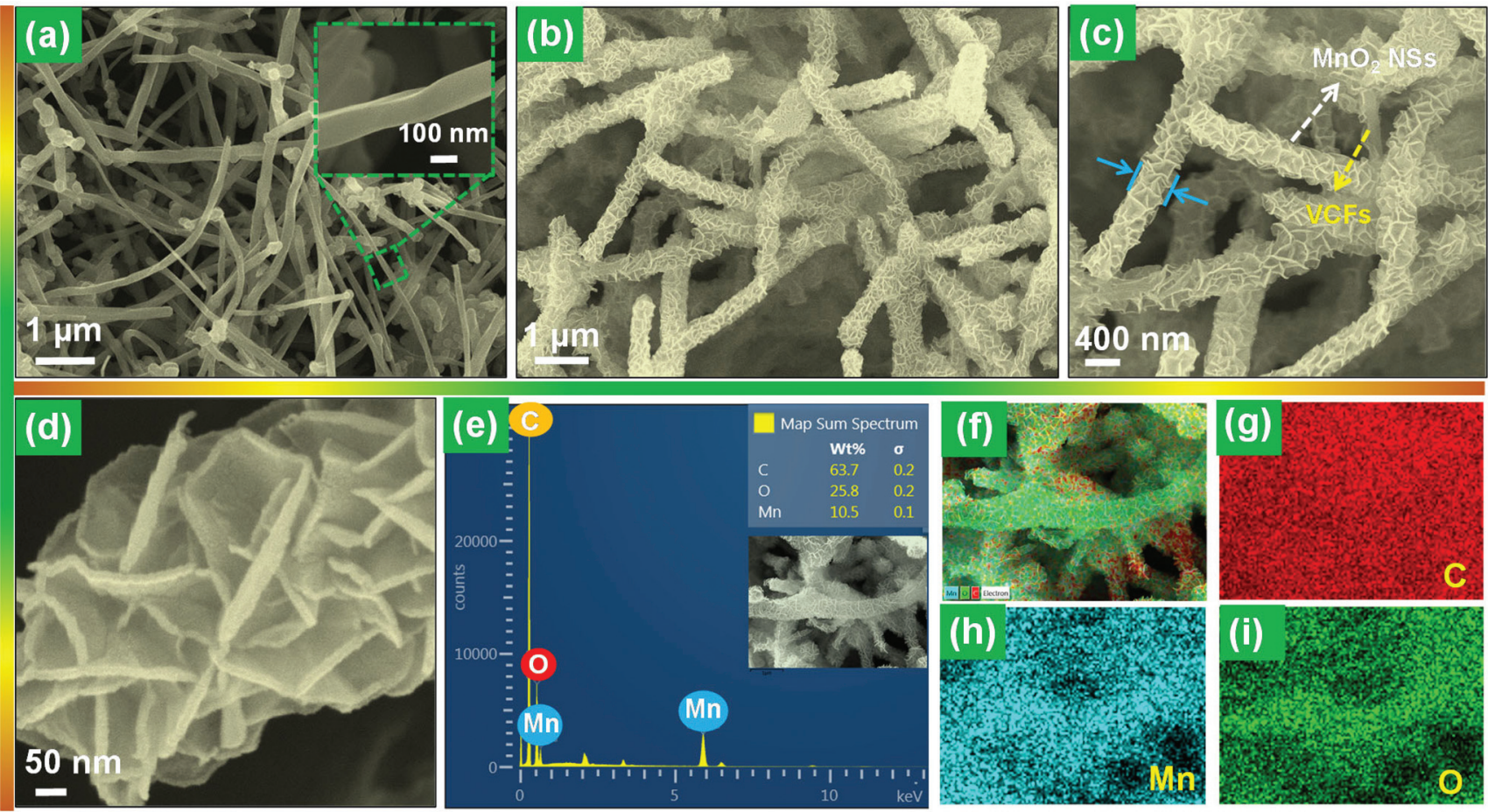

Fig. 2 FE-SEM images of (a) the pristine VCFs, (b) and (c) low and high magnifications of the $\mathrm{MnO}_{2} \mathrm{NSAs}$ (aVCFs and (d) very high magnification of a single VCF decorated with $\mathrm{MnO}_{2}$ NSAs. (e) EDX spectrum of the $\mathrm{MnO}_{2}$ NSAs@VCFs composite and (f) FE-SEM image of the corresponding EDX spectrum. (g), (h) and (i) EDX mapping images of $\mathrm{C}, \mathrm{Mn}$ and $\mathrm{O}$, respectively. Inset in (a) shows high magnification of a single VCF. 

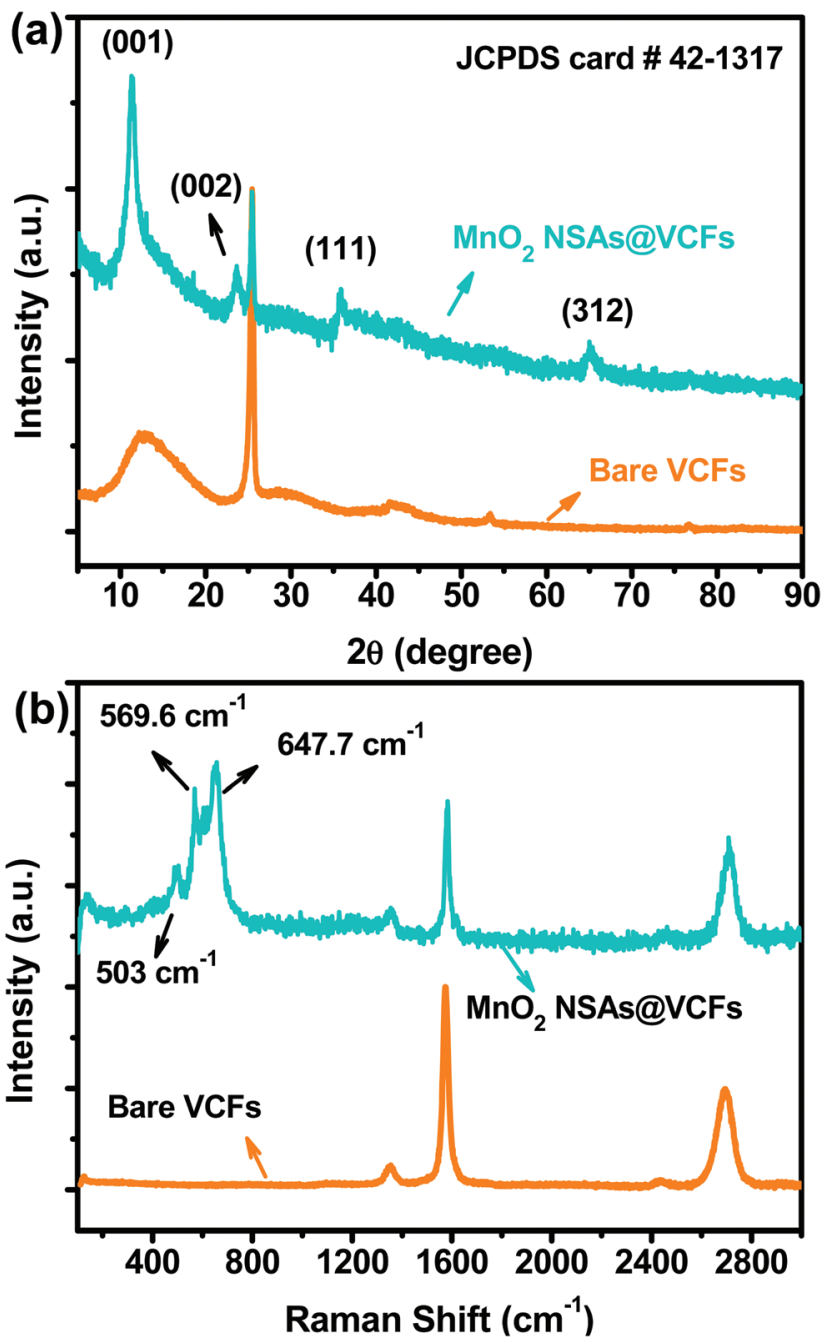

Fig. 3 (a) XRD patterns and (b) HR Raman spectra of the pristine VCFs and the $\mathrm{MnO}_{2}$ NSAs@VCFs.

of the bare VCFs and the $\mathrm{MnO}_{2}$ NSAs@VCFs composite. For the bare VCFs, the XRD pattern revealed broad peaks at $2 \theta$ degrees of $12.7,41.5,53.3$ and $76.7^{\circ}$ and a sharp peak at $25.4^{\circ}$, which are characteristic of a carbon based material. ${ }^{38}$ Meanwhile, the $\mathrm{MnO}_{2}$ NSAs@VCFs composite exhibited four peaks at $12,24.1,36.8$ and $66.2^{\circ}$ which are indexed to the crystal planes of (001), (002), (111) and (312) for $\mathrm{MnO}_{2}$, indicating the birnessite-type structure of the material (JCPDS card \# 42-1317). ${ }^{39}$ The structural properties of the as-prepared $\mathrm{MnO}_{2}$ NSAs@VCFs composite were further analyzed by HR Raman spectroscopy as shown in Fig. 3(b). It is well known that acid-treated VCFs have a carbon content illustrated by the Raman bands of $\mathrm{D}, \mathrm{G}$ and $\mathrm{G}_{0}$ at 1353, 1572 and $2695 \mathrm{~cm}^{-1}$, respectively. However, the $\mathrm{MnO}_{2}$ NSAs@VCFs composite showed additional vibrational Raman peaks at 503, 569.6 and $647.7 \mathrm{~cm}^{-1}$, which are ascribed to the presence of the birnessite-type $\mathrm{MnO}_{2}$. These results clearly demonstrate that the $\mathrm{MnO}_{2}$ NSAs were successfully grown on the VCFs without any impurities.
The electrochemical properties of the $\mathrm{MnO}_{2}$ NSAs@VCFs composite material was investigated using a three-electrode system in a $1 \mathrm{M} \mathrm{Na}_{2} \mathrm{SO}_{4}$ electrolyte solution at RT. Fig. 4(a) shows the comparison between the CV curves of the bare VCFs and the $\mathrm{MnO}_{2}$ NSAs@VCFs at a scan rate of $20 \mathrm{mV} \mathrm{s}^{-1}$. It can be seen that the bare VCFs showed no/slight response in current, indicating that the contribution of the VCFs to the capacitance is negligible. However, the CV curve of the $\mathrm{MnO}_{2}$ NSAs@VCFs exhibited relatively high integral CV areas and good rectangular and symmetric shapes, suggesting the fast and reversible surface redox reactions of ideal pseudocapacitive behavior. Usually, in many cases, the specific capacitance is proportional to the integrating area of the CV curve at the same scanning rate. ${ }^{37}$ So, it was found that the formed $\mathrm{MnO}_{2}$ NSAs@VCFs exhibited a higher capacitance than the pristine VCFs and also increased the rate of faradaic reactions due to the increased surface area. Fig. 4(b) shows the CV curves of the $\mathrm{MnO}_{2}$ NSAs@VCFs at different scan rates. It was noticed that the CV curves were enlarged without any distortion of their shapes as the scan rate was increased from 10 to $100 \mathrm{mV} \mathrm{s}^{-1}$. The excellent electrochemical reversibility of the composite is mainly due to its hierarchical architecture and good electrical conductivity, which contributes to the fast intercalation of electrolyte cations $\left(\mathrm{Na}^{+}\right)$with the material during reduction and deintercalation upon oxidation..$^{40,41}$ The GCD analysis was carried out to further confirm the higher electrochemical performance of the composite electrode. Fig. 4(c) shows the GCD curves of the hierarchical $\mathrm{MnO}_{2}$ NSAs@VCFs electrode between 0 to $1.0 \mathrm{~V}$ at different current densities in a $1 \mathrm{M}$ $\mathrm{Na}_{2} \mathrm{SO}_{4}$ electrolyte solution. The symmetric nature of all the charge-discharge cycles again shows linear and symmetrical features, demonstrating excellent reversibility and pseudocapacitive nature. The specific capacitance for each GCD curve was calculated from eqn (1) as mentioned above. Interestingly, the $\mathrm{MnO}_{2}$ NSAs@VCFs composite exhibited specific capacitance values of $115.3,113.5,110.2,108.7,107.4,103.3,100$ and 94.7 $\mathrm{F} \mathrm{g} \mathrm{g}^{-1}$ at different current densities of $0.5,1,1.5,2,3,5,7$ and $10 \mathrm{~A} \mathrm{~g}^{-1}$, respectively. The corresponding specific capacitance value as a function of applied current density is plotted in Fig. 4(d). The specific capacitance decreased gradually as the current density increased. This is either because the electrolyte ions are only absorbed on the outer surface of the material or an insufficient portion of the material is involved in the electrochemical reactions during the quick chargedischarge process. Meanwhile, the electrolyte ions can diffuse deeply inside the active material at a low current density, which results in a higher energy storage performance. ${ }^{42}$ But still, the composite material showed a rate capability of $82.1 \%$ at a current density of $10 \mathrm{~A} \mathrm{~g}^{-1}$, proving the advantages of composite materials for high-rate pseudocapacitors. The maximum capacitance of the $\mathrm{MnO}_{2}$ NSAs@VCFs composite is higher or comparable to those previously reported, as shown in Table S1. $\dagger$

The cycling stability is also one of the crucial factors which determine the suitability of active materials for practical applications. Accordingly, the long-term cycling process of the 

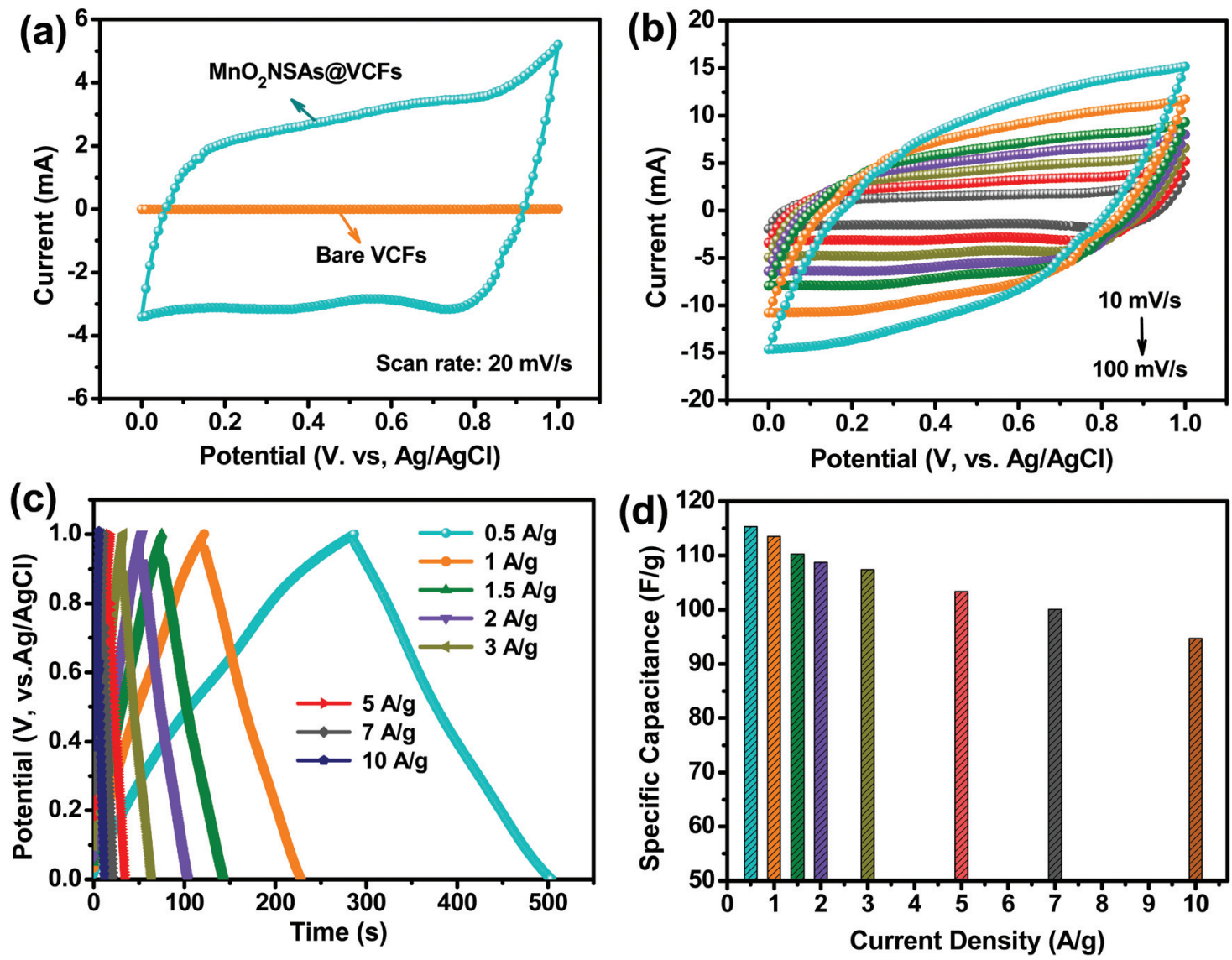

Fig. 4 Electrochemical properties of $\mathrm{MnO}_{2}$ NSAs@VCFs: (a) comparison of CV curves between the pristine VCFs and the MnO $\mathrm{NSAs}_{2} \mathrm{VCFs}$, (b) $\mathrm{CV}$ curves at various scan rates of $10-100 \mathrm{mV} \mathrm{s}^{-1}$, (c) GCD curves at different current densities of $0.5-10 \mathrm{~A} \mathrm{~g}^{-1}$ and (d) variation of the specific capacitance with current density.

$\mathrm{MnO}_{2}$ NSAs@VCFs electrode was carried out via repetitive GCD cycles at a high current density of $5 \mathrm{~A} \mathrm{~g}^{-1}$ in a $1 \mathrm{M}$ $\mathrm{Na}_{2} \mathrm{SO}_{4}$ electrolyte solution. The variation in the capacitance retention with increasing the cycle number up to 2000 cycles for the $\mathrm{MnO}_{2}$ NSAs@VCFs composite electrode is displayed in Fig. 5(a). After 2000 cycles, the composite material still exhibited a capacitance retention of $85.6 \%$, indicating the long-term cycling stability of the composite material for practical applications. The electrochemical behavior and conductivity of the hierarchical $\mathrm{MnO}_{2}$ NSAs@VCFs composite was investigated using EIS analysis over a frequency range of $0.01 \mathrm{~Hz}$ to $100 \mathrm{kHz}$ with a perturbation amplitude of $5 \mathrm{mV}$ versus opencircuit potential. Fig. 5(b) shows the Nyquist plots of the $\mathrm{MnO}_{2}$ NSAs@VCFs before and after the long-term cycling process. The plot includes a semicircle in the high frequency region and a sloped line in the low frequency region. The sloped lines (Warburg impedance) for both the curves are due to the ion transportation between the electrolyte and electrode depending on the frequency. Before cycling, the equivalent series resistance (electrolyte resistance, electrode resistance and contact resistance between the electrolyte and electrode), which is measured from the intercept of the curve with the real axis, was observed as $5.05 \Omega$. But, after completion of the cycling test, this value was slightly increased to $6.13 \Omega$ which may be due to the formation of a solid electrolyte interface. This would act as an obstacle between the active material and electrolyte. The charge transfer resistance $\left(R_{\mathrm{ct}}\right)$ between the electrolyte and active material was measured from the diameter of the semicircle shape of the curve. The $R_{\mathrm{ct}}$ value of the composite electrode before cycling was $3.46 \Omega$ and, after cycling, it was about $3.67 \Omega$, which still remains low. This is indicative of the excellent electrochemical conductivity of the $\mathrm{MnO}_{2}$ NSAs@VCFs composite even after a long-term cycling process. The higher capacitance, rate capability and cycling stability of the composite electrode could be due to the following structural features, as schematically illustrated in Fig. 5(c). At first, the VCFs provide higher conductivity and can be beneficial for the formation of continuous charge transfer pathways. The hierarchical and ultrathin characteristics of the $\mathrm{MnO}_{2}$ NSAs on the VCFs increase the surface area, making them completely available to absorb the electrolyte ions $\left(\mathrm{Na}^{+}\right)$ for reversible electrochemical reactions via faster electron and ion transport. Moreover, the electrolyte $\mathrm{Na}^{+}$ions can easily penetrate into the small gaps formed by the interwoven arrangement of the $\mathrm{MnO}_{2}$ NSAs on the surface of the VCFs, which results in enhanced electrochemical kinetics and 

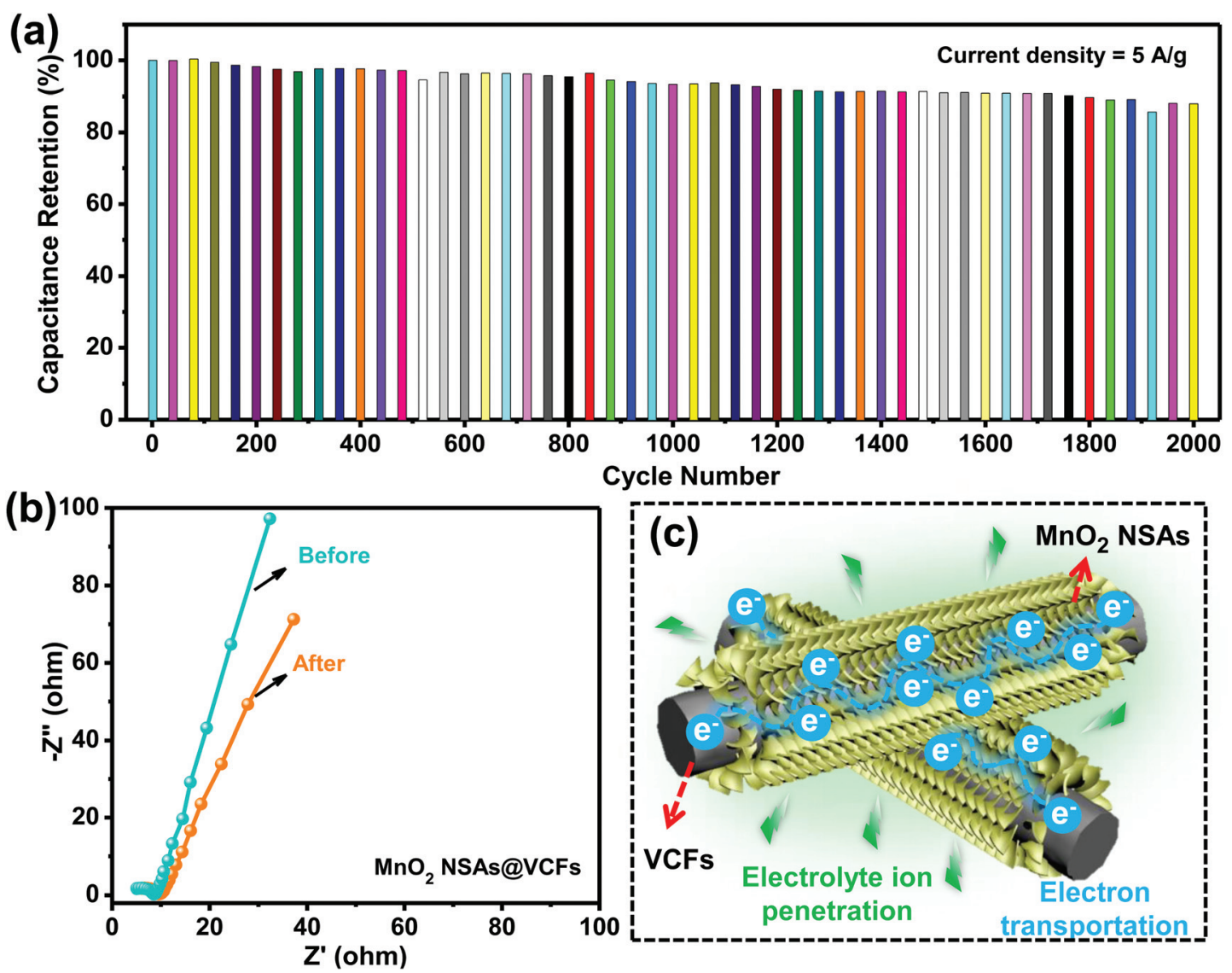

Fig. 5 (a) Cycling behavior of the working electrode at $5 \mathrm{~A} \mathrm{~g}^{-1}$ current density in $1 \mathrm{M} \mathrm{Na}_{2} \mathrm{SO}_{4}$ up to 2000 cycles and (b) EIS of the MnO NSAs@VCFs composite before and after the cycling test. (c) Schematic representation of electron transportation at the VCFs and penetration of electrolyte ions through the $\mathrm{MnO}_{2} \mathrm{NSAs}$.

improved energy storage properties. All in all, this costeffective approach to fabricate electrochemically conductive composite materials paves a new pathway for high-performance supercapacitor applications.

\section{Conclusion}

In summary, hierarchical $\mathrm{MnO}_{2}$ NSAs@VCFs composite materials were synthesized by a simple and green wet-chemical method at low temperature. Cost-effective VCFs provided a good conductive surface and helped $\mathrm{MnO}_{2}$ NSA growth over the top of them. The interconnected arrangement of the ultrathin $\mathrm{MnO}_{2}$ NSAs@VCFs leads to high surface area and good electrochemical conductivity to exhibit the higher electrochemical performance as a pseudocapacitive material in a $1 \mathrm{M}$ $\mathrm{Na}_{2} \mathrm{SO}_{4}$ electrolyte solution. The maximum specific capacitance based on the active material weight was about $115.3 \mathrm{~F} \mathrm{~g}^{-1}$ at $0.5 \mathrm{~A} \mathrm{~g}^{-1}$ for the $\mathrm{MnO}_{2}$ NSAs@VCFs composite. Moreover, the fabricated material composite also showed good rate capability and cycling stability at higher current densities. Consequently, the prepared composite material is a promising candidate for high-performance energy storage applications.

\section{Acknowledgements}

This work was supported by the National Research Foundation of Korea (NRF) grant funded by the Korea government (MSIP) (No. 2015R1A5A1037656).

\section{References}

1 Z. Gao, C. Bumgardner, N. Song, Y. Zhang, J. Li and X. Li, Nat. Commun., 2016, 7, 11586.

2 T. Chen and L. Dai, Mater. Today, 2013, 16, 272-280.

3 P. Simon and Y. Gogotsi, Nat. Mater., 2008, 7, 845-854.

4 X. Luo, J. Wang, M. Dooner and J. Clarke, Appl. Energy, 2015, 137, 511-536.

5 A. S. Arico, P. Bruce, B. Scrosati, J.-M. Tarascon and W. van Schalkwijk, Nat. Mater., 2005, 4, 366-377.

6 J. Jiang, Y. Li, J. Liu, X. Huang, C. Yuan and X. W. Lou, Adv. Mater., 2012, 24, 5166-5180.

7 G. Nagaraju, S. M. Cha, S. C. Sekhar and J. S. Yu, Adv. Energy Mater., DOI: 10.1002/aenm.201601362.

8 M. M. Shaijumon, F. S. Ou, L. Ci and P. M. Ajayan, Chem. Commun., 2008, 2373-2375, DOI: 10.1039/b800866c. 
9 G. Xu, B. Ding, J. Pan, J. Han, P. Nie, Y. Zhu, Q. Sheng and H. Dou, J. Mater. Chem. A, 2015, 3, 23268-23273.

10 J. Cherusseri and K. K. Kar, J. Mater. Chem. A, 2015, 3, 21586-21598.

11 J. Vatamanu, M. Vatamanu and D. Bedrov, ACS Nano, 2015, 9, 5999-6017.

12 G. K. Veerasubramani, K. Krishnamoorthy and S. J. Kim, RSC Adv., 2015, 5, 16319-16327.

13 P. Y. Chan, Rusi and S. R. Majid, Solid State Ionics, 2014, 262, 226-229.

14 E. Frackowiak, Phys. Chem. Chem. Phys., 2007, 9, 1774-1785.

15 M. Rajkumar, C.-T. Hsu, T.-H. Wu, M.-G. Chen and C.-C. Hu, Prog. Nat. Sci.: Mater. Int., 2015, 25, 527-544.

16 J. Ji, L. L. Zhang, H. Ji, Y. Li, X. Zhao, X. Bai, X. Fan, F. Zhang and R. S. Ruoff, ACS Nano, 2013, 7, 6237-6243.

17 A. L. M. Reddy and S. Ramaprabhu, J. Phys. Chem. C, 2007, 111, 7727-7734.

18 Y. Liu, R. Wang and X. Yan, Sci. Rep., 2015, 5, 11095.

19 G. Nagaraju, Y. H. Ko and J. S. Yu, J. Power Sources, 2015, 283, 251-259.

20 G. Nagaraju, G. S. R. Raju, Y. H. Ko and J. S. Yu, Nanoscale, 2016, 8, 812-825.

21 S. Chen, J. Zhu, X. Wu, Q. Han and X. Wang, ACS Nano, 2010, 4, 2822-2830.

22 R. Jiang, T. Huang, J. Liu, J. Zhuang and A. Yu, Electrochim. Acta, 2009, 54, 3047-3052.

23 X. Zhang, J. Ma, W. Yang, Z. Gao, J. Wang, Q. Liu, J. Liu and X. Jing, CrystEngComm, 2014, 16, 4016-4022.

24 S. Zhu, W. Cen, L. Hao, J. Ma, L. Yu, H. Zheng and Y. Zhang, Mater. Lett., 2014, 135, 11-14.

25 S. Maiti, A. Pramanik and S. Mahanty, ACS Appl. Mater. Interfaces, 2014, 6, 10754-10762.

26 X. Lu, M. Yu, G. Wang, T. Zhai, S. Xie, Y. Ling, Y. Tong and Y. Li, Adv. Mater., 2013, 25, 267-272.
27 G. Yu, L. Hu, N. Liu, H. Wang, M. Vosgueritchian, Y. Yang, Y. Cui and Z. Bao, Nano Lett., 2011, 11, 44384442.

28 H. Xia, Y. Wang, J. Lin and L. Lu, Nanoscale Res. Lett., 2012, $7,1$.

29 T. Takei, A. Miura and N. Kumada, Colloids Surf., A, 2012, 396, 341-345.

30 A.-Q. Zhang, Y.-H. Xiao, L.-Z. Lu, L.-Z. Wang and F. Li, J. Appl. Polym. Sci., 2013, 128, 1327-1331.

31 J. M. Ko and K. M. Kim, Mater. Chem. Phys., 2009, 114, 837-841.

32 J.-H. Jeong and E.-S. Oh, J. Appl. Electrochem., 2015, 45, 983-990.

33 I. Cho, J. Choi, K. Kim, M.-H. Ryou and Y. M. Lee, RSC Adv., 2015, 5, 95073-95078.

34 G. Nagaraju, Y. H. Ko, S. M. Cha, S. H. Im and J. S. Yu, Nano Res., 2016, 9, 1507-1522.

35 G. Nagaraju, Y. H. Ko and J. S. Yu, CrystEngComm, 2014, 16, 11027-11034.

36 Y. Chen, Y. Zhang, D. Geng, R. Li, H. Hong, J. Chen and X. Sun, Carbon, 2011, 49, 4434-4442.

37 L. Li, Z. A. Hu, N. An, Y. Y. Yang, Z. M. Li and H. Y. Wu, J. Phys. Chem. C, 2014, 118, 22865-22872.

38 H. Xia, Y. Wang, J. Lin and L. Lu, Nanoscale Res. Lett., 2012, 7, 1-10.

39 P. Wu, S. Cheng, L. Yang, Z. Lin, X. Gui, X. Ou, J. Zhou, M. Yao, M. Wang, Y. Zhu and M. Liu, ACS Appl. Mater. Interfaces, 2016, 8, 23721-23728.

40 M. Toupin, T. Brousse and D. Bélanger, Chem. Mater., 2004, 16, 3184-3190.

41 D. Guo, X. Yu, W. Shi, Y. Luo, Q. Li and T. Wang, J. Mater. Chem. A, 2014, 2, 8833-8838.

42 G. Nagaraju, R. Kakarla, S. M. Cha and J. S. Yu, Nano Res., 2015, 8, 3749-3763. 